\title{
Effects of interrun interval on serial learning
}

\author{
STEVEN J. HAGGBLOOM and MICHAEL W. EKDAHL \\ Arkansas State University, State University, Arkansas
}

\begin{abstract}
Two groups of five rats each received a decreasing quantity of food reward, 14-7-3-1-0 .045-g food pellets, over successive runs in a runway. The interrun interval (IRI) separating runs within each of two daily pattern repetitions (trials) was $10 \mathrm{sec}$ (short, $S$ ) or 4-5 min (long, L) and varied over four successive phases of training in the order indicated by the group names, that is, Groups SLSS and LLLS. Anticipation of the 0-pellet element developed more rapidly in Group SLSS than in Group LLLS, but did eventually occur at the long IRI. Anticipation was eliminated by the increase in IRI experienced by Group SLSS in Phase 2 and by the decrease in IRI experienced by Group LLLS in Phase 4. The results are discussed with reference to the effects of changes in stimulus context accompanying IRI shifts on retrieval of task-specific knowledge and with reference to the possible signal value established to IRI-specific stimuli.
\end{abstract}

Rats given a decreasing number of $.045-\mathrm{g}$ food pellets (e.g., 14-7-3-1-0) over successive runs in a runway learn to anticipate the terminal, 0 -pellet element, as evidenced by markedly slower response times on that run than on earlier runs in the series (e.g., Hulse \& Dorsky, 1977). That rats can learn to anticipate one or more elements in a series is well established, but there is considerable disagreement about what is learned.

Hulse and his associates (Fountain \& Hulse, 1981; Hulse, 1978; Hulse \& Dorsky, 1977, 1979) suggested that rats learn a rule that defines the formal structure of a pattern. For instance, on the strong monotonic pattern 14$7-3-1-0$, the rat learns that each element in the pattern is smaller than the immediately preceding element, or the rule $\mathrm{E}(\mathrm{i})>\mathrm{E}(\mathrm{i}+1)$. Capaldi and his associates (e.g., Capaldi \& Molina, 1979; Capaldi, Nawrocki, \& Verry, 1982) hypothesized that rats learn a series of stimulusstimulus (S-S), or interitem, associations, with each element in the series being signaled by the memory of one or more preceding elements. On this view, the memory of 1 pellet, or perhaps the memory of a sequence such as 3-1 (see Capaldi \& Verry, 1981; Capaldi, Verry, \& Nawrocki, 1982) serves as a negative discriminative stimulus $(\mathbf{S}-$ ) signaling 0 pellets on the fifth run.

Hulse (1980) suggested that procedural differences, among them length of the interrun interval (IRI) separating successive elements in the pattern, might account for some of the disparities between his findings and those of Capaldi's group. Hulse and Dorsky (1977), for example, used a 10-sec IRI and reported that formally simple strong monotonic patterns (14-7-3-1-0) were learned more rapidly than structurally more complex, weakly monotonic, or nonmonotonic patterns (14-5-5-1-0 and 14-1-3-

This experiment was supported by a Faculty Research Grant to the first author from Arkansas State University. Michael W. Ekdahl is now at Stephen F. Austin University. Requests for reprints should be addressed to the first author, Department of Psychology, Arkansas State University, P.O. Box 2127, State University, AR 72467.
7-0). Capaldi and Molina (1979), on the other hand, used an IRI of 4-5 min and reported faster learning of weakly monotonic (15-15-0-0 or 14-14-2-0) and nonmonotonic (1-29-0) patterns than of strong monotonic patterns (15$10-5-0$ or $20-10-0$ ).

Roitblat, Pologe, and Scopatz (1983, Experiments 1 and 2) investigated the effects of short (10-15 sec) and long (4-5 min) IRIs on rats' rates of learning strong monotonic (14-7-3-1-0) and nonmonotonic (14-1-3-7-0) patterns. Nonmonotonic patterns were not learned at either IRI (Experiment 1); monotonic patterns were learned at the short IRI, but not at the long IRI (Experiments 1 and 2). In both experiments, IRI was confounded with number of trials per day. Although we do not doubt the conclusion that IRI was the relatively more important variable, the confounded designs make it impossible to determine whether the obtained differences overestimated or underestimated the effects of IRI on serial learning.

Moreover, Roitblat et al. (1983) did not report whether there was any evidence that rats in the long IRI groups in either experiment learned to anticipate the 0-pellet element by the end of their 60 training trials (each pattern repetition constitutes a trial). In single alternation tasks (Capaldi \& Lynch, 1966; Capaldi \& Spivey, 1964; Capaldi \& Stanley, 1963) and other discrimination problems in which correct responding is extensively regulated by the pattern of reinforcement events (e.g., Haggbloom, 1978, 1979), learning is retarded by a long intertrial interval (ITI), but does eventually develop. One purpose of the experiment reported here was to determine whether rats trained on the strong monotonic pattern 147-3-1-0 at a long IRI would eventually learn to anticipate the 0 -pellet element.

A second purpose of the present experiment was to investigate the effects of IRI shifts on the performance of a learned sequence. Roitblat et al. (1983, Experiment 3) reported that correct anticipation of 0 pellets in a monotonic 14-7-3-1-0 pattern learned under a short IRI was eliminated by a shift to the long IRI. They suggested that 
a learned pattern was represented in memory as a list of items in serial position and that correct responding depended on the rat's ability to keep track of its position in the list. According to this view, long IRIs interfere with both learning and performance of a serial anticipation task by making it difficult for the rat to remember and utilize serial position cues.

Roitblat et al. (1983) rejected an alternative interpretation of their IRI-shift results which we regard as quite viable-namely, that the increase in IRI eliminated anticipation of the 0-pellet element because the IRI shift altered the stimulus conditions from those under which the task was learned. This possibility was discarded because they considered it unlikely that manipulation of an incidental variable such as IRI could have so large an effect on behavior, while, in their fourth experiment, manipulation of a central variable, substituting 0 pellets on Runs 1,2 , 3 , or 4 for the food quantity that normally occurred there, had no effect on behavior. Yet it is well known that a change in either direction in the interval separating successive runs or trials in a runway, even though an incidental variable, produces a marked behavioral disruption (e.g., Amsel, Wong, \& Traupmann, 1971; Capaldi, Berg, \& Sparling, 1971; Capaldi \& Haggbloom, 1975; Capaldi \& Morris, 1976; Haggbloom \& Pond, 1981; Lewis \& Cotton, 1959; Rothkopf, 1955). ${ }^{1} \mathrm{We}$ investigated the possibility that a shift in IRI in either direction would eliminate correct anticipation of the 0-pellet element in the 14-7-3-1-0 pattern.

There were two groups in the present experiment, Groups LLLS and SLSS, both trained on the 14-7-3-1-0 pattern. The groups are identified with regard to the IRI (long, L, vs. short, S) experienced over four successive phases of training. The groups were shifted at different points in training to provide for unshifted comparison conditions without having to run two additional groups. The initial shift to a long IRI replicates the essential IRI-shift feature of the Roitblat et al. experiment, and postponing the shift to a short IRI to the last phase of training increases the liklihood that the long-IRI group will have learned to anticipate the 0-pellet element at the time of the shift.

\section{METHOD}

\section{Subjects}

The subjects were 10 male albino rats, approximately 70 days old at the beginning of the experiment, bred in the laboratory from Holtzman stock.

\footnotetext{
Apparatus

Rats were tested in a straight enclosed runway modeled after that used by Hulse and Dorsky (1977). The runway was $92 \mathrm{~cm}$ long, with a $30-\mathrm{cm}$ startbox and a $30-\mathrm{cm}$ goal area separated from the rest of the runway by manually operated guillotine doors. The goal area contained an $11-\mathrm{cm}$ niche at a right angle to the runway and an unpainted goal cup positioned against the end wall of the goal area. The goal cup was constructed by drilling a 6 -cm-diam hole in a small block of wood. The inside width of the runway was $10 \mathrm{~cm}$, and the inside height was $11 \mathrm{~cm}$. The runway was painted flat black throughout. The start and goal areas were covered with pieces of
}

hinged Plexiglas, and the runway proper was covered with hardware cloth. Raising the guillotine door between the startbox and the runway triggered a .01-sec timer, which was stopped when the rat entered the goalbox and interrupted a photobeam $20 \mathrm{~cm}$ into the goal area. Food reinforcement consisted of an appropriate number of .045-g Noyes pellets.

\section{Procedure}

Ten days prior to training, the rats were placed on a fooddeprivation schedule, consisting of $12 \mathrm{~g}$ of rat food per day, which was maintained throughout the experiment. The amount of food received in the goalbox as reinforcement was subtracted from the daily ration. Water was always available.

On each of 3 days immediately preceding training, the rats were handled in squads of two for 4 min per squad. Exploration of the apparatus was provided on the 2 days prior to the beginning of training. On the 1st day of exploration, both guillotine doors were open and individual animals were allowed to run through the apparatus for $5 \mathrm{~min}$, obtaining four food pellets scattered at random and one pellet located in the food cup. This procedure was repeated once, with the rat being returned to its home cage for a 10-15-min interval between exploration periods. On the 2 nd day of exploration, the rats were placed in the startbox and then released when the startbox door was raised. During a single 5-min exploration period, they could eat 14 food pellets located in the food cup.

On the day following exploration, the training phase of the experiment began. Five rats were assigned randomly to each of two groups, identified as Groups SLSS and LLLS. L and S represent, respectively, a long (4-5 min) IRI and a short (10 sec) IRI, and the group label indicates the order in which the IRIs were experienced by both groups over four successive phases of training. On each day of training, each animal received two trials. Each trial consisted of five runs on the monotonically decreasing reinforcement pattern 14-7-3-1-0. The rats were confined to the goalbox for $10 \mathrm{sec}$ in the case of nonreinforcement. If a rat failed to complete a run within $60 \mathrm{sec}$, it was placed in the goalbox. There were 16 days of training in Phase 1,2 days of testing at the long IRI in Phase 2, 3 days of retraining under the original Phase 1 IRIs in Phase 3, and a single test day at the short IRI in Phase 4.

\section{RESULTS}

In Phase 1, running times to the first four pattern elements were nearly identical both between and within groups. Figure 1 shows running times for both groups to the 14-pellet element as a reference point and to the 0pellet element over the course of Phase 1 in blocks of 2 days. As can be seen, Group SLSS ran consistently and substantially more slowly to the 0-pellet element than to other elements throughout Phase 1. Anticipation of the 0 -pellet element in Group LLLS, on the other hand, while it did eventually develop, was not evident until about Block 6. The inset in Figure 1 shows running times for both groups to all five pattern elements averaged over the 32 trials of Phase 1.

An analysis of variance (ANOVA) with IRI as a between-subjects factor and runs, trials, and days as within-subjects factors was applied to the Phase 1 running times. The different behavior patterns over runs shown in the inset in Figure 1 were reflected in a highly reliable IRI $\times$ runs interaction $[F(4,32)=8.39$, $\mathrm{p}<.001]$. Partitioning this interaction into simple effects showed a significant runs effect for Group $\operatorname{SLSS}[F(4,32)$ $=27.13, \mathrm{p}<.001]$ but no differences over runs for 


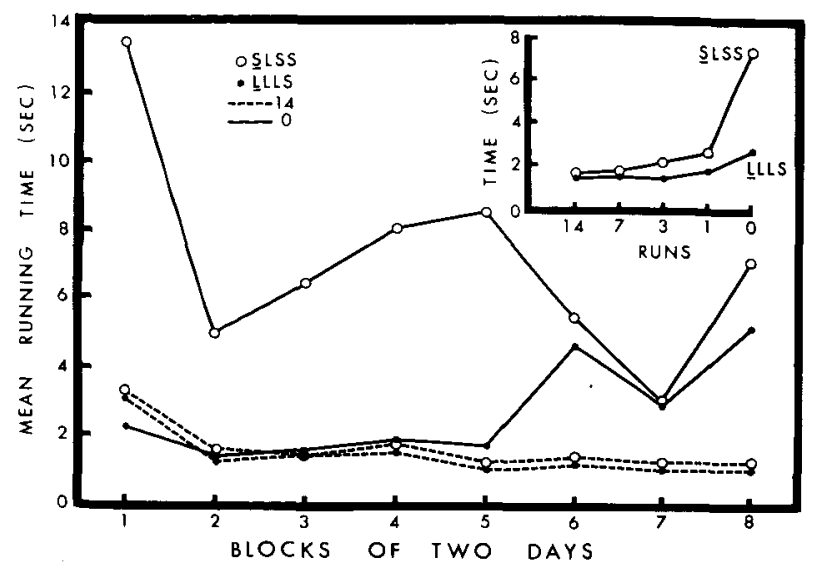

Figure 1. Running times for both groups on 14- and 0-pellet runs averaged over blocks of 2 days (four trials) and, inset, on each of the five runs averaged over all 32 Phase 1 trials. The underscored letter in the group label indicates the operative IRI.

Group LLLS $[\mathrm{F}(4,32)=1.29]$. A post hoc comparison for Group SLSS between Run 5 (mean $=7.27$ ) and the pooled mean for Runs 1-4 (mean $=2.06$ ) showed that running times were significantly slower to the 0 -pellet element than to other elements $[\mathrm{F}(1,32)=34.16, \mathrm{p}<.001]$. Simple effects of IRI at each run showed that there were no differences due to IRI on Runs 1-4 [largest $F(1,32)$ $=1.23$ on Run 3]; but differences due to IRI were highly reliable on Run $5[\mathrm{~F}(1,32)=38.76, \mathrm{p}<.001]$. Although Group LLLS did learn to run slowly to the 0-pellet element late in training, as evidenced below, the IRI $\times$ runs $X$ days interaction was not significant $[\mathrm{F}(60,480)=$ 1.32].

Figure 2 shows running times for both groups to each pattern element averaged over the last 2 days of Phase 1 (left panel) and averaged over the 2 days of Phase 2 (right

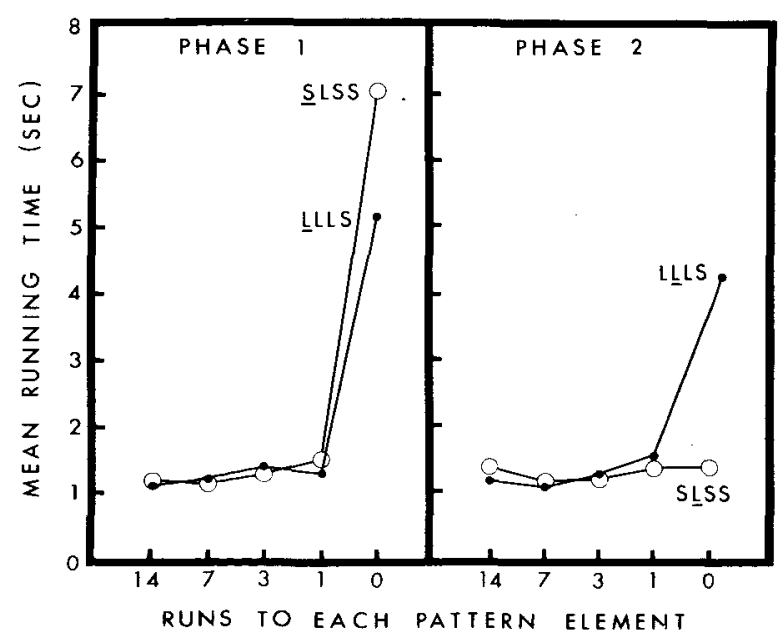

Figure 2. Running times for both groups on each of the five runs averaged over the last 2 days of Phase 1 (left panel) and on both days of Phase 2 (right panel). The underscored letter in the group label indicates the operative IRI. panel). Figure 2 clearly illustrates that anticipation of the 0 -pellet element was well developed in both IRI conditions by the end of Phase 1. It can also be seen that the short-to-long IRI shift eliminated correct anticipation of 0 pellets in Group SLSS.

An ANOVA with IRI as a between-subjects factor and runs, trials, and phase (preshift vs. postshift) as withinsubjects factors was applied to the data shown in Figure 2. The change in behavior pattern over runs from preshift to postshift in Group SLSS resulted in a reliable IRI $\times$ runs $\times$ phase interaction $[F(4,32)=3.83, p<.05]$. Partitioning this interaction into simple interactions of runs $\times$ phase at both IRI conditions confirmed that the pattern of responding over runs changed from preshift to postshift in Group SLSS $[F(4,32)=10.81, p<.001]$ but not in Group LLLS $(F<1)$. A post hoc comparison for Group SLSS between Run 5 (mean $=7.19$ ) and the pooled mean for Runs $1-4$ (mean $=1.28$ ) on the last 2 days of Phase 1 was highly significant $[F(1,32)=88.54$, $\mathrm{p}<.001]$. A similar comparison for Group LLLS between Run 5 (mean $=5.15$ ) and Runs $1-4($ mean $=1.25)$ was also highly reliable $[\mathrm{F}(1,32)=38.55, \mathrm{p}<.001]$.

The same comparisons performed on the data for Phase 2 showed that Run 5 times (mean $=4.24$ ) remained slower than those on Runs 1-4 (mean $=1.28$ ) in Group LLLS $[F(1,32)=26.94, p<.001]$ but that postshift Run 5 times (mean $=1.38$ ) did not differ from Runs 1-4 (mean $=1.3$ ) in Group SLSS $(F<1)$. Simple effects of IRI at each run showed that at the end of Phase 1 Groups SLSS and LLLS did not differ from one another over Runs 1-4 (all Fs $<1$ ) and that the groups did not differ on Run $5[F(1,32)=4.13, p>.05]$. In Phase 2, Group LLLS ran more slowly to the 0-pellet element than did Group SLSS $[F(1,32)=8.13, p<.01]$, but there were no differences between the groups on Runs 1-4 (all Fs $<1$ ).

Figure 3 shows running times for both groups on each of the five runs averaged over all 3 days of Phase 3 (left panel) and on the single day of Phase 4 (right panel). As can be seen, the shift from a long to a short IRI eliminated anticipation of the 0-pellet element in Group LLLS.

An ANOVA with groups as a between-subjects factor and runs, trials, and phase as within-subjects factors was applied to running times on the last day of Phase 3 and the single day of Phase 4 . The change in behavior in Group LLLS from preshift to postshift was reflected in a reliable groups $\times$ runs $\times$ phase interaction $[F(4,32)=$ $4.54, \mathrm{p}<.01]$. Partitioning this interaction into simple interactions confirmed that the groups did not differ over runs in Phase 3, $[\mathrm{F}(4,32)=1.62]$ but did respond differently over runs in Phase $4[F(4,32)=3.71, p<.05]$. The simple interactions of runs $\times$ phase confirmed that the response pattern changed from Phase 3 to Phase 4 in Group LLLS $[F(4,32)=3.05, p<.05]$ but not in Group SLSS $[F(4,32)=1.67]$. Both groups ran more slowly on Run 5 relative to the pooled mean of Runs 1-4 in Phase 3 [smallest $\mathrm{F}(1,32)=6.51, \mathrm{p}<.05$, in Group SLSS]. In 


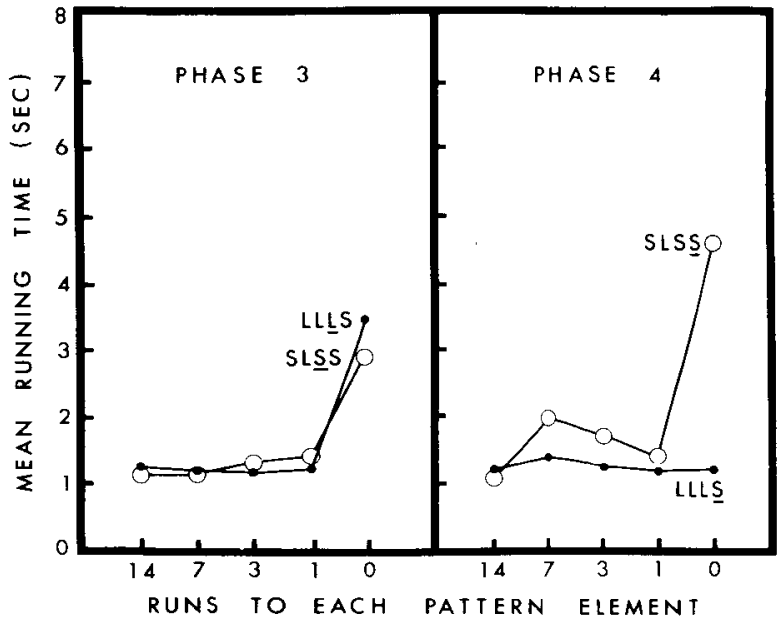

Figure 3. Running times for both groups on each of the five runs averaged over all 3 days of Phase 3 (left panel) and on the single day of Phase 4 (right panel). The underscored letter in the group label indicates the operative IRI.

Phase 4, Group SLSS continued to run more slowly on Run 5 than on Runs $1-4[\mathrm{~F}(1,32)=24.88, \mathrm{p}<.001]$, but times on Run 5 did not differ from those on Runs 1-4 in Group LLLS $(\mathrm{F}<1)$.

\section{DISCUSSION}

The finding here that a monotonic pattern is learned faster at a short IRI than at a long IRI is in agreement with results reported by Roitblat et al. (1983). The present experiment, however, indicates that performance at a relatively long IRI is eventually as good as it is at a very short IRI. Also in agreement with Roitblat et al., a shift from the short to the long IRI eliminated anticipation of the 0pellet element in the present experiment. However, a subsequent shift from the long to the short IRI similarly eliminated anticipation here.

As Roitblat et al. noted, the finding that serial learning is impaired at a long IRI is not necessarily problematic for any one of the three models of serial learning mentioned here. The rat's ability to recall prior elements and employ them as discriminative stimuli, or to recall their positions in the list, or to identify and apply rules, can reasonably be assumed to decrease as the IRI increases. Any one of those assumptions could also explain the disruptive effects of an increase in IRI, but none would predict that a decrease in IRI would interfere with performance on a learned pattern.

The fact that an IRI shift in either direction can eliminate the rat's ability to anticipate 0 -pellets in a well-learned sequence is very reminiscent of the behaviorally disruptive effects of ITI shifts in other instrumental learning situations (e.g., Amsel et al., 1971; Capaldi et al., 1971; Capaldi \& Haggbloom, 1975; Capaldi \& Morris, 1976; Haggbloom \& Pond, 1981; Lewis \& Cotton, 1959; Rothkopf, 1955). In those experiments, as in the present one, time was an incidental variable, but nevertheless exercised substantial control over behavior. The disruptive behavioral effects of ITI shifts in those investigations were attributed to changes in ITI-related stimuli accompanying the shift. The disruptive behavioral effects of IRI shifts in serial learning may also be due to stimulus change, but the reasons for this, the underlying processes, remain to be identified.

One candidate for the process by which serial anticipation behavior is adversely affected by stimulus change is suggested by contextual effects on memory retrieval. There is good evidence that memories are less likely to be retrieved the more the retrieval context differs from the context in which the memory was occasioned (e.g., Spear, 1978). Following training at a particular IRI, the rat's knowledge, in the form of S-S associates, rules, or lists, of the relationship among pattern elements may be stored with contextual information that includes IRIspecific stimuli. The change in IRI-related stimuli accompanying an IRI shift in either direction might prevent adequate retrieval of knowledge required to anticipate elements of the series, and thus a shift in either direction would disrupt behavior.

It is possible that the disruptive behavioral effects of an increase or a decrease in IRI are not due to the same process. For example, Capaldi (personal communication, October 21,1984 ) suggested that a group trained at a short IRI with multiple pattern repetitions separated by a relatively long interval learns to anticipate the initial pattern element, for example, 14 pellets in the present experiment, following a long interval. That learning then interferes with slow running to the 0-pellet element when subjects are shifted to a long IRI.

The rat appears to be very sensitive to time-related stimuli. In discrimination learning situations, rats can use ITI-related cues as positive and negative discriminanda (Haggbloom, 1978, 1982). In serial anticipation or pattern learning tasks, time-related stimuli can be employed as phrasing cues to help distinguish one pattern element from another (Bowen \& Strickert, 1966), one pattern repetition from another (Capaldi, Verry, Nawrocki, \& Miller, 1984), and one pattern from another (Haggbloom, 1979). The control exercised by time-related stimuli may even overshadow stimulus control by pattern elements, under some conditions (Capaldi et al., 1984). We suggest that any explanation of IRI-shift effects on serial learning will have to address the possible signal value established to time-related stimuli during the preshift phase, as well as possible effects of stimulus change on some such underlying process as memory retrieval.

\section{REFERENCES}

Amsel, A., Wong, P. T., P., \& Traupmann, K. L. (1971). Shortterm and long-term factors in extinction and durable persistence. Journal of Experimental Psychology, 90, 90-95.

BOWEN, J., \& STRICKERT, D. (1966). Discrimination learning as a function of internal stimuli. Psychonomic Science, 5, 297. 
Capaldi, E. J. (1971). Memory and learning: A sequential viewpoint. New York: Academic Press.

Capaldi, E. J., \& HaGgBloom, S. J. (1975). Response events as well as goal events as sources of animal memory. Animal Learning \& Behavior, 3, 1-10.

CAPAldi, E. J., \& LyNCH, D. (1966). Patterning at a 24-hour ITI: Resolution of a discrepancy more apparent than real. Psychonomic Science, 6, 299-230.

Capaldi, E. J., \& Molina, P. (1979). Element discriminability as a determinant of serial pattern learning. Animal Learning \& Behavior, 7, 318-322.

CAPAldi, E. J., \& MORRIS, M. D. (1976). A role of stimulus compounds in eliciting responses: Relatively spaced extinction following massed extinction. Animal Learning \& Behavior, 4, 113-117.

Capaldi, E. J., Nawrocki, T. M., \& Verry, D. R. (1982). Difficult serial anticipation learning in rats: Rule encoding vs. memory. Animal Learning \& Behavior, 10, 167-170.

CAPAldi, E. J., \& SpIVEY, J. E. (1964). Stimulus consequences of reinforcement and nonreinforcement: Stimulus traces or memory. Psychonomic Science, 1, 403-404.

Capaldi, E. J., \& Stanley, L. R. (1963). Temporal properties of reinforcement aftereffects. Journal of Experimental Psychology, 65, $169-175$.

CAPAldi, E. J., \& VerRY, D. R. (1981). Serial order anticipation learning in rats: Memory for multiple hedonic events and their order. Animal Learning \& Behavior, 9, 441-453.

Capaldi, E. J., Verry, D. R., \& Nawrocki, T. M. (1982). Multiple hedonic memory: Memory for more than one hedonic event in rats. Animal Learning \& Behavior, 10, 351-357.

Capaldi, E. J., Verry, D. R., Nawrocki, T. M., \& Miller, D. J. (1984). Serial learning, interitem associations, phrasing cues, interference, overshadowing, chunking, memory, and extinction. Animal Learning \& Behavior, 12, 7-20.

Fountain, S. B., \& Hulse, S. H. (1981). Extrapolation of serial stimulus patterns by rats. Animal Learning \& Behavior, 9, 381-384.

HaGGBLOOM, S. J. (1978). Intertrial interval effects on internal stimulus control of behavior in brightness differential conditioning. Leaming and Motivation, 9, 347-358.

HaGGBloOM, S. J. (1979). The differential reinforcement of rewardproduced and response-produced stimuli. Learning and Motivation, 10, 364-381.

HAGGBLOOM, S. J. (1982). Intertrial interval shift effects on discrimi- nation reversal: Motivational and associative control by internal stimuli. Bulletin of the Psychonomic Society, 20, 269-271.

HaGgbloom, S. J., \& Pond, E. K. (1981). Partial reinforcement effects following a shift from massed acquisition to spaced extinction. Bulletin of the Psychonomic Society, 18, 278-280.

HuLSE, S. H. (1978). Cognitive structrure and serial pattern learning by rats. In S. H. Hulse, H. Fowler, \& W. K. Honig (Eds.), Cognitive processes in animal behavior. Hillsdale, NJ: Erlbaum.

Hulse, S. H. (1980). The case against the missing rule: Memory for reward vs. formal structure in serial pattern learning. Animal Learning \& Behavior, 8, 689-690.

HulsE, S. H., \& DORSKY, N. P. (1977). Structural complexity as a determinant of serial pattern learning. Learning and Motivation, 8 , 488-506.

HulSE, S. H., \& DORSKy, N. P. (1979). Serial pattern learning by rats: Transfer of a formally defined stimulus relationship and the significance of nonreinforcement. Animal Learning \& Behavior, 7, 211-220.

LEWIS, D. C., \& CotTon, J. W. (1959). The effect of intertrial interval and number of acquisition trials with partial reinforcement on performance. Joumal of Comparative and Physiological Psychology, 52 , 398-401.

Roirblat, H. L., Pologe, B., \& Scopatz, R. A. (1983). The representation of items in serial position. Animal Learning \& Behavior, 11 , 489-498.

RothKOPF, E. Z. (1955). Distribution of practice and temporal decay of response produced stimuli. Journal of Experimental Psychology, 49, 33-38.

SPEAR, N. E. (1978), Processing of memories: Forgetting and retention. Hillsdale, NJ: Erlbaum.

\section{NOTE}

1. In recent serial pattern learning investigations, the time between runs to successive elements of the pattern has been called the interrun interval (IRI) and the time between successive pattern repetitions (trials) has been called the intertrial interval (ITI). In most instrumental runway situations, however, each run is called a trial and the time between trials (runs) is the ITI.

(Manuscript received July 20, 1984; revision accepted for publication November 6,1984 .) 